\title{
An Astounding Percutaneous Endoscopic Gastrostomy Complication: A Pseudoaneurysm of Gastroduodenal Artery
}

\author{
Mafalda João ${ }^{a}$ Susana Alves ${ }^{a}$ Vítor Carvalheiro ${ }^{b}$ Miguel Areia $^{a}$ \\ ${ }^{a}$ Gastroenterology Department, Portuguese Oncology Institute of Coimbra, Coimbra, Portugal; ${ }^{b}$ Radiology \\ Department, Coimbra Hospital and University Centre, Coimbra, Portugal
}

\section{Keywords}

Percutaneous endoscopic gastrostomy · Gastrointestinal bleeding . Pseudoaneurysm of gastroduodenal artery .

\section{Uma complicação inesperada de gastrostomia endoscópica percutânea: pseudoaneurisma da artéria gastroduodenal}

\section{Palavras chave}

Gastrostomia endoscópica percutânea · Hemorragia gastrointestinal · Pseudoaneurisma da artéria gastroduodenal

A 58-year-old male with dysphagia due to a hypopharyngeal squamous cell carcinoma underwent a percutaneous endoscopic gastrostomy (PEG) tube placement by the pull technique into the anterior gastric wall between the corpus and antrum without immediate complications (Fig. 1). Two and three weeks later, he was admitted with hypotension and melena, with no changes in the gastrostomy site and hemoglobin of 5.1 and $6.0 \mathrm{~g} / \mathrm{dL}$ (baseline value: 8.5 ), respectively. Tumor friability bleeding was assumed; the patient received red blood cells, started an oral antifibrinolytic agent, and was discharged. A month after the procedure, he was readmitted with similar symptoms,

karger@karger.com www.karger.com/pjg

Karger"

BOPEN ACCESS
(C) 2020 The Author(s)

Published by S. Karger AG, Basel

This article is licensed under the Creative Commons AttributionNonCommercial-NoDerivatives 4.0 International License (CC BYNC-ND) (http://www.karger.com/Services/OpenAccessLicense). Usage and distribution for commercial purposes as well as any distribution of modified material requires written permission. a new drop of $3 \mathrm{~g} / \mathrm{dL}$ in hemoglobin, and a $10-\mathrm{mm}$ palpable mass under the external PEG tube. An abdominal computed tomography revealed a $17 \times 7 \times 10 \mathrm{~mm}$ pseudoaneurysm arising from the gastroduodenal artery (Fig. 2). An angiography showed contrast extravasation from the gastroduodenal artery (Fig. 3) and embolization with coils (Fig. 4) was successfully performed. Three months after the procedure the patient remains asymptomatic.

Hemorrhage following gastrostomy tube placement occurs in $0.6-1.2 \%$ of cases. Bleeding originates mostly from the gastrostomy tract or from gastric ulceration [1]. Less common causes of bleeding include gastric artery perforation, superior mesenteric artery perforation, retroperitoneal hemorrhage, aortic perforation, abdominal wall pseudoaneurysm, and gastric wall and rectus sheath hematomas. PEG site hemorrhage caused by a pseudoaneurysm is exceedingly rare with only few cases reported in the literature. They resulted from direct arterial injury during the PEG tube placement. Given that the PEG tube placement typically involves the anterior wall of the stomach, the possibility of an arterial puncturing seems low. However, the rotated structure of the stomach and/or an angiectopia can explain an inadvertent arterial puncture. In all described cases, patients underwent PEG tube placement with the "pull" technique and presented few 


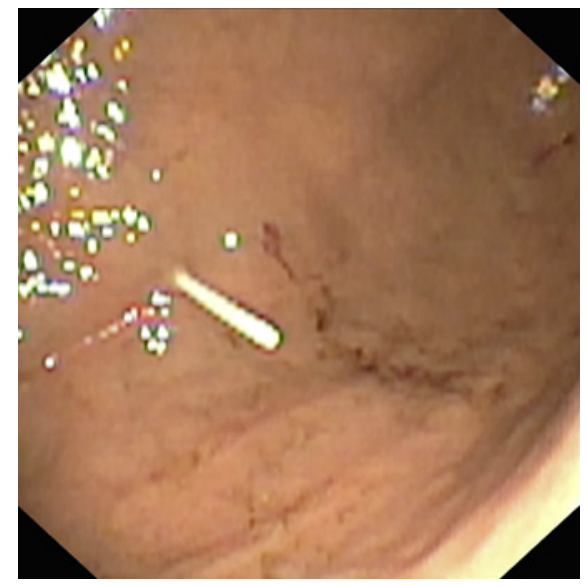

Fig. 1. Endoscopic image showing the site of percutaneous endoscopic gastrostomy placement in the anterior gastric wall between corpus and antrum.

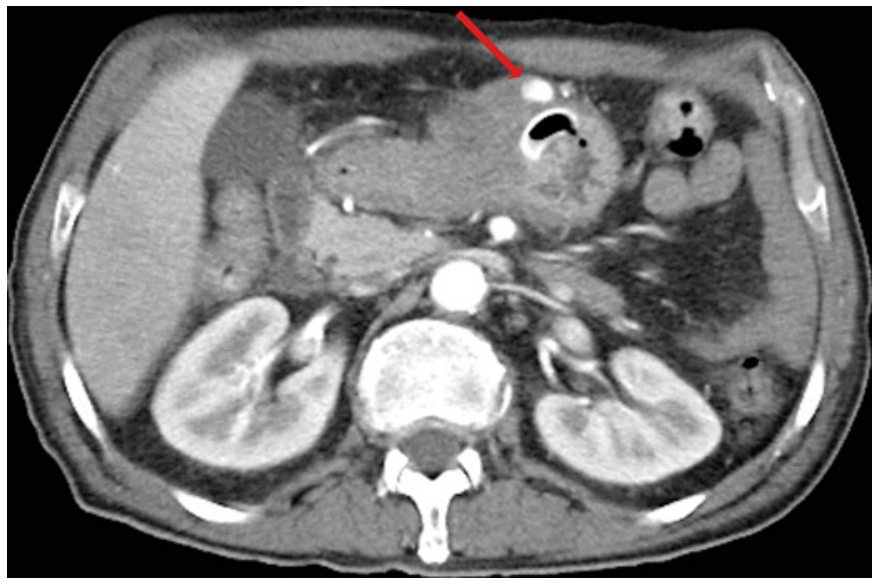

Fig. 2. An abdominal computed tomography revealing a pseudoaneurysm in the PEG site (red arrow).
Fig. 3. Angiography revealing contrast extravasation (red arrow) from the gastroduodenal artery (yellow arrow).

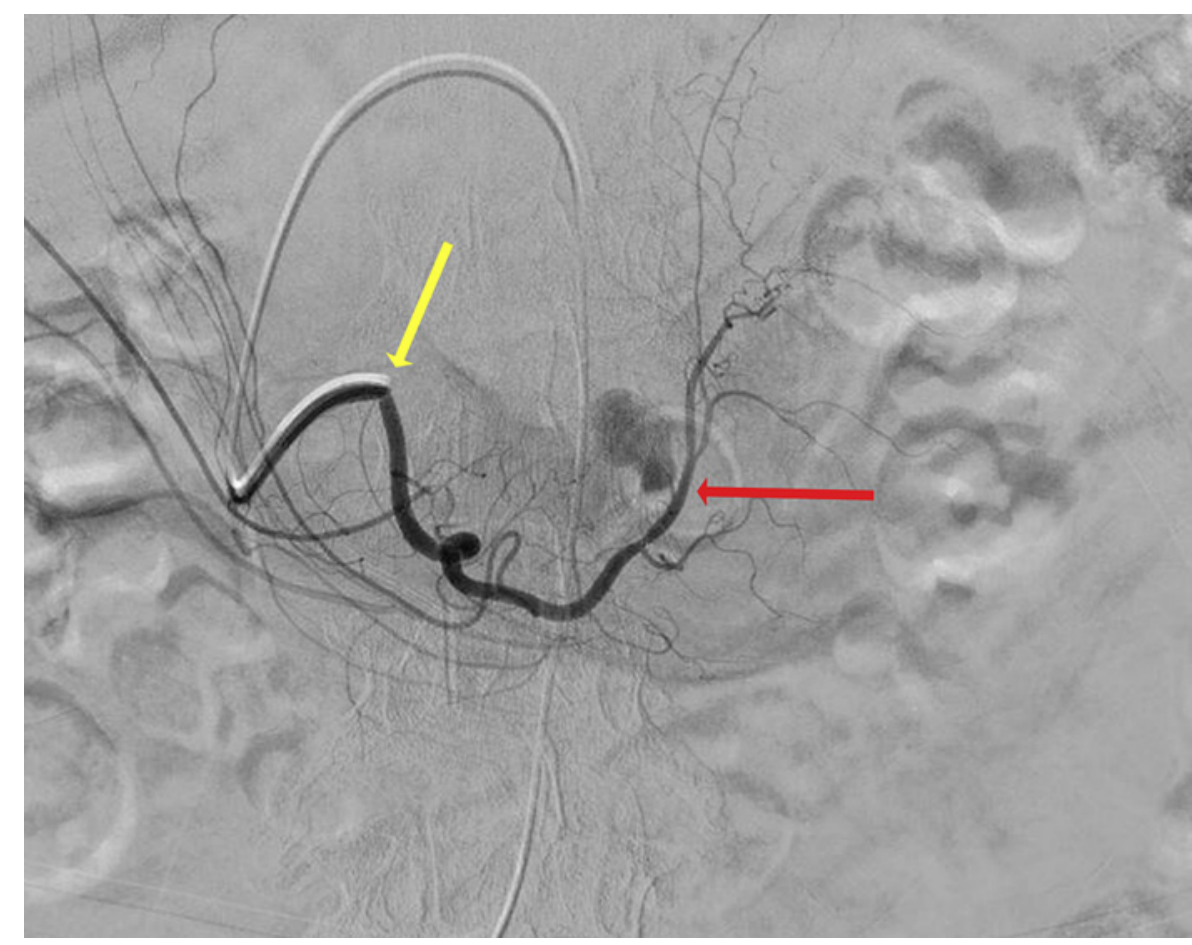

weeks later with recurrent episodes of upper gastrointestinal bleeding. Computed tomography angiography and Doppler ultrasound contributed to establish the definitive diagnosis. In most cases, the treatment involved interventional radiology with angiographic embolization or surgery $[2,3]$. Percutaneous thrombin injection was used as an alternative to surgical or endovascular therapy in a patient with kidney injury and obesity [4].
PEG site hemorrhage caused by a pseudoaneurysm is a differential diagnosis to keep in mind in a patient with recurrent upper gastrointestinal bleeding after PEG tube placement. The diagnosis of this potentially fatal complication implies a high suspicion index due to its nonspecific presentation and rarity. Angiographic embolization constitutes an effective therapy. 
Fig. 4. Angiography after gastroduodenal artery embolization (red arrows) with coils (blue arrow).

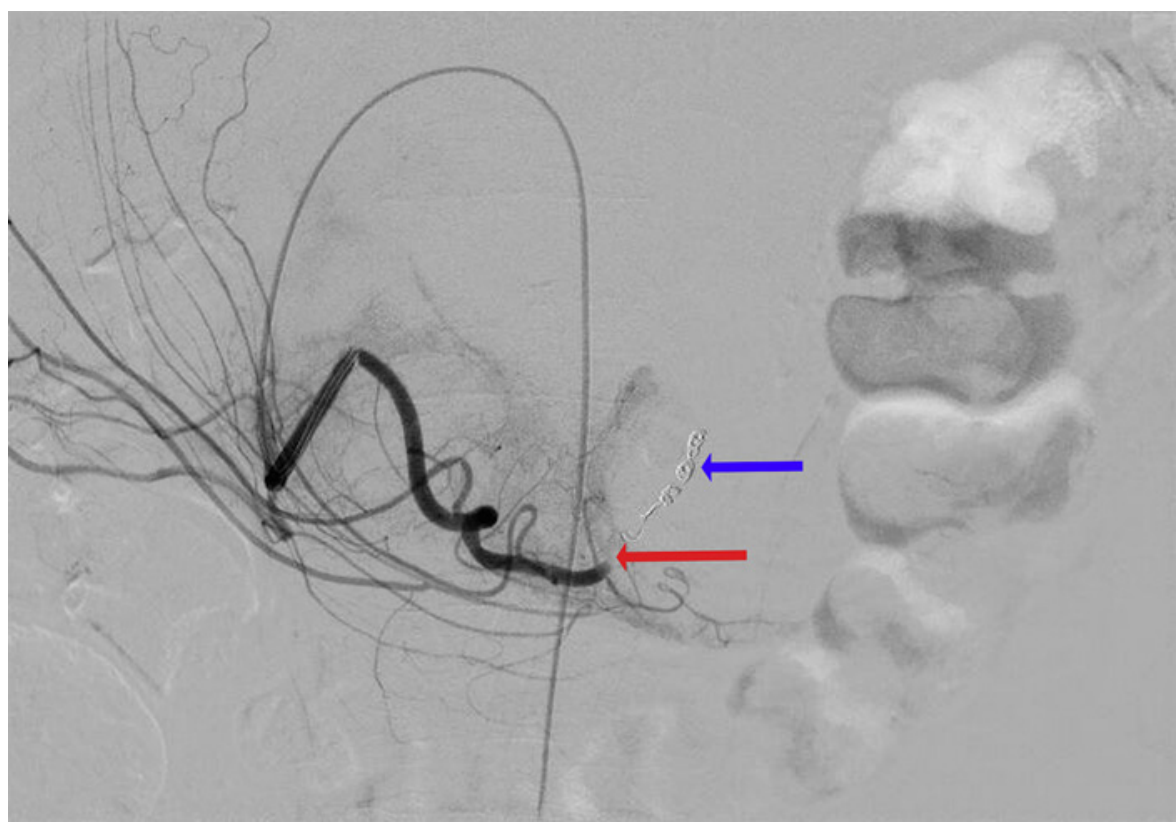

\section{Statement of Ethics}

Informed consent was obtained from the patient to publish these information and imaging.

\section{Conflict of Interest Statement}

The authors have no conflicts of interest to declare.

\section{Funding Sources}

There were no funding sources.

\section{Author Contributions}

Mafalda João drafted the manuscript, Susana Alves, Vítor Carvalheiro, and Miguel Areia critically revised the manuscript and approved the final version to be submitted.

\section{References}

1 Rahnemai-Azar AA, Rahnemaiazar AA, Naghshizadian R, Kurtz A, Farkas DT. Percutaneous endoscopic gastrostomy: indications, technique, complications and management. World J Gastroenterol. 2014 Jun;20(24): 7739-51.

2 Shigoka H, Maetani I, Saito M. Pseudoaneurysm developed after percutaneous endoscopic gastrostomy: a report of two cases. Eur J Gastroenterol Hepatol. 2013 Dec;25(12): 1484-7.
3 Zivari K, Niknam N, Lapin S, Rahmani R, Mayer I. Ruptured Gastric Artery Pseudoaneurysm: A Life threatening Complication of Percutaneous Endoscopic Gastrostomy (PEG): 1874. Am J Gastroenterol. 2017 Oct; 112:112.

4 Fatade F, Axelrod D, Lien K, Kaplan D, Nagula $\mathrm{S}$. Percutaneous endoscopic gastrostomy tube placement complicated by a gastric pseudoaneurysm and recurrent hemorrhage. Endoscopy. 2012;44 Suppl 2 UCTN:E38-9. 